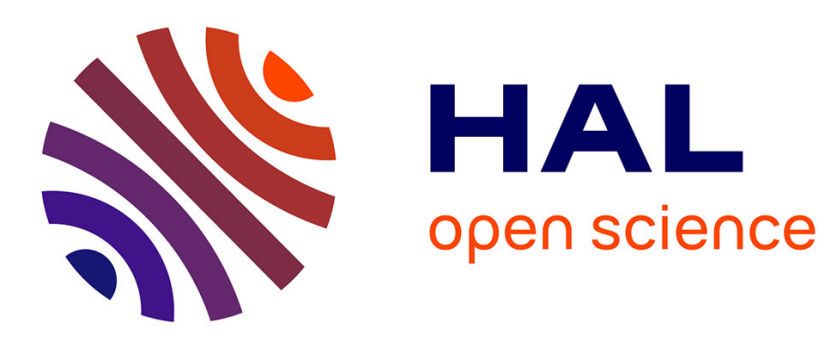

\title{
Collaborative Networks and Active Knowledge Architectures - A Road Building Case
}

Sobah Abbas Petersen, Frank Lillehagen, Minh Vu Bui, John Krogstie

\section{To cite this version:}

Sobah Abbas Petersen, Frank Lillehagen, Minh Vu Bui, John Krogstie. Collaborative Networks and Active Knowledge Architectures - A Road Building Case. 16th Working Conference on Virtual Enterprises (PROVE), Oct 2015, Albi, France. pp.297-308, 10.1007/978-3-319-24141-8_27 . hal-01437898

\section{HAL Id: hal-01437898 \\ https://inria.hal.science/hal-01437898}

Submitted on 17 Jan 2017

HAL is a multi-disciplinary open access archive for the deposit and dissemination of scientific research documents, whether they are published or not. The documents may come from teaching and research institutions in France or abroad, or from public or private research centers.
L'archive ouverte pluridisciplinaire HAL, est destinée au dépôt et à la diffusion de documents scientifiques de niveau recherche, publiés ou non, émanant des établissements d'enseignement et de recherche français ou étrangers, des laboratoires publics ou privés.

\section{(c)(1)}

Distributed under a Creative Commons Attribution| 4.0 International License 


\title{
Collaborative Networks and Active Knowledge Architectures - A Road Building Case
}

\author{
Sobah Abbas Petersen ${ }^{1}$, Frank Lillehagen ${ }^{2}$, Minh Vu Bui ${ }^{3}$, John Krogstie ${ }^{3}$ \\ ${ }^{1}$ SINTEF Technology and Society, Trondheim, Norway \\ ${ }^{2}$ Commitment AS, Lysaker, Norway \\ ${ }^{3}$ Dept. of Computer and Information Systems, \\ Norwegian University of Science and Technology, Norway
}

\begin{abstract}
The planning, designing and building of roads is an extensive process that takes several years and involve several actors from industry and the public sector. This paper reports the collaboration with the Norwegian Road Authority on using the Active Knowledge Architecture approach and Visual Modelling methods to support road planning, design and building. The experience is based on the work conducted on real parts of the E6 Motorway, being built north of Trondheim, Norway. The purpose of the knowledge architectures presented in this paper is to improve collaboration and to share knowledge among all the stakeholders in the process. Road planning projects will benefit from agile collaborative networks and active knowledge bases built by knowledge models and architectures. Important lessons learned include the need for holistic design methods, instant data-driven collaboration, and agile approaches and work environments for continuous planning, design and building.
\end{abstract}

Keywords: Collaborative networks, Active knowledge Architecture, Road planning and building, Holistic design, Model-based architecture-driven solutions and Visual models.

\section{Introduction}

The planning, designing and building of roads is an extensive process that takes several years and involves several actors from industry and the public sector. The current practices take the approach of different phases in the process where different actors are involved. The procedures and other relevant knowledge are documented in a set of handbooks. While the desire to make the process more effective, a change may take time, and perhaps involve new ways of working and leveraging the knowledge of the actors. The interactions and alliances among the actors could benefit from ideas addressed by researchers in collaborative networks [1] and knowledge visualisation approaches such as Enterprise Modelling, e.g. [2] and Active Knowledge Architectures [3]. This paper reports the collaboration with the Norwegian Road Authority on using Active Knowledge Architectures and visual modelling to support road planning, design and building.

During the last 25 years, novel enterprise concepts, agile approaches, IT methods and digital technologies have been developed and applied for new application areas 
and purposes. Improving the business processes of public organizations, capturing, enhancing, and visualizing data and information flows are common challenges.

Industry sectors, in particular the aerospace and automotive sectors, have been very active participants in networked enterprise $R \& D$ projects; for example in several European projects such as ATHENA [4]. However, the public sector has only recently become engaged in such collaborative research projects. The reasons why most public sector agencies are slow in adopting novel approaches, methods and technologies, and innovation platforms are probably due to the size of the organizations and the fact that strategic and business objectives and values to be delivered are decided in political programs. This knowledge is not directly accessible or visible to the project planners, designers and developers of technologies or the various stakeholders such as the citizens.

The experiences presented in this paper are from the public sector of road planning and building. The main objectives of the research work performed were to explore Active Knowledge Architecture (AKA) driven work environments for road planning, design and building. The focus of this paper is on the many key roles of the Norwegian Road Authorities, and their need to improve knowledge sharing and competence management among road entrepreneurs and suppliers and the various stakeholders of the process. An ongoing road building project was selected for testing the approach and gathering of experiences and work practices. The work reported in the paper are based on a Masters thesis [5].

\section{Planning and Building of Roads - Current Practices}

The experiences presented in this paper describe a real case on building roads, based on information contributed by The Norwegian Road Authorities (SVV, Statens Vegvesen in Norwegian). The road planning and building process is shown in Fig. 1. As most public sector projects, it is a layered approach, where each layer is managed and executed by horizontal slicing of activities. The tasks are shown in the top row, whereas the main actors involved per task are shown in the bottom row.

\begin{tabular}{|c|c|c|c|c|c|c|c|c|}
\hline $\begin{array}{l}\text { Concept } \\
\text { Choice \& } \\
\text { Validation }\end{array}$ & $\begin{array}{l}\text { County } \\
\text { Systems } \\
\text { Plans }\end{array}$ & $\begin{array}{l}\text { Community } \\
\text { Regulatory } \\
\text { Plans }\end{array}$ & $\begin{array}{l}\text { Road } \\
\text { Building } \\
\text { Plans }\end{array}$ & $\begin{array}{l}\text { Building } \\
\text { road } \\
\text { parsell }\end{array}$ & $\begin{array}{l}\text { Road } \\
\text { Handover }\end{array}$ & $\begin{array}{l}\text { Daily } \\
\text { Operations }\end{array}$ & $\begin{array}{l}\text { Cont. } \\
\text { Maitenance }\end{array}$ & $\begin{array}{l}\text { Reinvest } \\
\text { Modify }\end{array}$ \\
\hline $\begin{array}{l}\text { SVV, } \\
\text { community } \\
\text { and } \\
\text { counties }\end{array}$ & Consultant & Consultant & Consultant & $\begin{array}{l}\text { Entre- } \\
\text { preneur }\end{array}$ & $\begin{array}{l}\text { Meeting } \\
\text { contract } \\
\text { parties }\end{array}$ & $\begin{array}{l}\text { Entre- } \\
\text { preneur }\end{array}$ & $\begin{array}{l}\text { Entre- } \\
\text { preneur }\end{array}$ & $\begin{array}{l}\text { Entre- } \\
\text { preneur }\end{array}$ \\
\hline
\end{tabular}

Fig. 1 - Traditional horizontally sliced road planning and building process

Projects start with Concept Choice Validation (CCV), a methodical government evaluation in the early phases of major road projects and major transport systems in rural areas and cities. In a CCV, all transportation and citizens' needs and societal influences are considered as are the possible solutions and their main concepts. The 
evaluation and the following quality assurance measures form the knowledge base for decision making and the scope for road planning based on county plans or community regulation plans covering the entire transportation sector.

The main knowledge is in the minds of people assigned to the major roles as road owner, consultants and entrepreneur as indicated in Fig. 1. Supporting the people is a series of elaborate documents maintained and produced by SVV. Currently, there are 153 documents and the road owner, consultants and entrepreneurs must be familiar with the contents of these documents. They are divided into three categories:

- 11 building norms documents describe the principles for building roads for annual average traffic, type of transportation, and operational rules;

- 37 legislative and prescriptive documents for planning and building roads;

- 105 documents with SVV approved guidelines and data collected from experiences in building and maintaining roads.

These handbooks provide the necessary information and data for planning, project execution and building of roads, including support for decision making in the planning stage. Most of these handbooks have close to 200 pages.

$\mathrm{SVV}$, as owner, is responsible for all strategic planning of roads, building and management, and for communication with the stakeholders and users, from community and county service providers to the common citizen. Arriving at an agreed plan and concepts that are accepted by all parties can take many years and costs hundreds of millions of Norwegian kroner. Planning, data collection, design and knowledge sharing are major challenges and most of the time, the actual costs of planning and constructing the road is much higher than the respective budgets.

A specific section of the E6 Motorway, north of Trondheim Airport at Stjørdal, was selected as the case for modelling the first knowledge architecture for road planning and building. The SVV officials from the Trondheim project office, as responsible road builders, were the main sources of planning and building competence and provided the domain knowledge for our modelling efforts. However they were not involved in the modelling itself.

The questions they wanted answers to were:

- $\quad$ Can SVV implement faster, more effective planning and improved understanding and communication among stakeholders involved?

- Does the AKM technology give significant time savings in planning and building, improved knowledge sharing, and a more holistic understanding of the road planning and building tasks?

- Will AKM capabilities improve collaboration in design and building, enable knowledge sharing and reuse, and support competence transfer for rapid team building?

\section{Modelling Road Knowledge Architectures}

Some illustrative examples of the models produced and an overall structure of the relevant knowledge architectures are described. The main objectives of the modelling, the resulting architectures, and architecture-driven solutions are to investigate the 
possibility to represent the main knowledge as active models, and get initial feedback from the core stakeholders on the potential of the approach including:

- How active knowledge architectures might improve the planning and building of roads, and enhance the present knowledge base,

- Show support for holistic thinking, design principles, and novel road design methodologies supporting collaborative planning, design and execution,

- Show how existing handbooks, processes and community and county plans can become valuable knowledge models,

- Show support for traceability, decision/support, predictability and reuse, and autonomous data and knowledge management,

- Enable faster and easier access to knowledge and data, and work-centric views providing improved collaboration and execution,

- Show that planning, design, construction and operation architectures can be built, used and maintained by users applying simple graphic modelling

\subsection{Active Knowledge Modelling}

Active Knowledge Modelling (AKM) is based on the nature of Enterprise Knowledge Spaces, and practical Work and Collaboration Spaces [3] and [6]. Most of the AKM ideas and design methodologies have evolved through experiences in practical modelling projects with leading international enterprises such as Volvo Cars, Boeing Aircraft, and US Air Force (see [3] for descriptions). AKM can be used to create AKAs of enterprises. Of particular importance to AKA are the properties of practical workspaces, such as reflective views of enterprise knowledge, repetitive task-patterns, replicable templates, and reusable knowledge models. AKM emphasises visual models that bring together different concepts and their dependencies that are easily visualised by different roles in role-specific workspaces. Such models facilitate adaptation of methods and contents to produce role-specific views.

\subsection{Modelling for Road Planning}

Modelling is ideally performed by a team of people that include several roles, e.g. [7]. The roles that were involved in this work were:

- The owner: the ones responsible for the road building architecture and for contracting consultants and entrepreneurs.

- Modelling expert: someone who could provide expert knowledge in modelling process, methods and tools.

- Facilitator: someone who is experienced in using the selected modelling process and tool and facilitating the modelling process.

- Modeller: develop the enterprise models in the selected tool during the modelling of architecture.

- Domain experts: someone who could provide knowledge about the domain under consideration, such as bridges and tunnels, which is basis for modelling. 
In this case, however, it was not possible to have all these members as active members of the modelling team simultaneously. The owners, SVV, were also the domain experts. Due to time constraints on their part, they guided the modeller, mostly the Masters student and modelling experts who were the advisors, to the relevant handbooks on road design and building, which served as the main source of domain knowledge. Several meetings were held between the modelling team and the owners to verify if the model was relevant for them and contained relevant and correct domain knowledge. The owners included four people with competencies from working with road planning and building, who had over 25 years of experience.

METIS $^{1}$ was selected as the modelling tool as it is based on the ideas of AKM and is also the preferred tool by the modelling experts based on their experiences.

\section{The Initial Model}

The model was designed to represent the knowledge required to execute the processes identified in the CVV shown in Fig. 1, and to support the different roles involved in the processes. An overview of the model is shown in Fig. 2. The left hand side of the model contains generic information that applies to all roads and this information was obtained mostly from the relevant handbooks and discussions with the owners and domain experts. The contents of this part of the model were structured to represent the governing rules and regulations for the specific road. Planning processes and references to similar projects, the goals and expectations from the project owner's perspective and from roles that should be involved were modelled. The right hand side of the model contains the actual road case, i.e. contents specific to the particular part of the road between Havnekryss and Kvithammer. This part contains the specific governing information for that project, the work processes and tasks and the corresponding roles and the road building plan. One of the rationales of this structure for the model is to enable reuse of information and experiences so that similar road projects can use parts of this model as a start for their specific models.

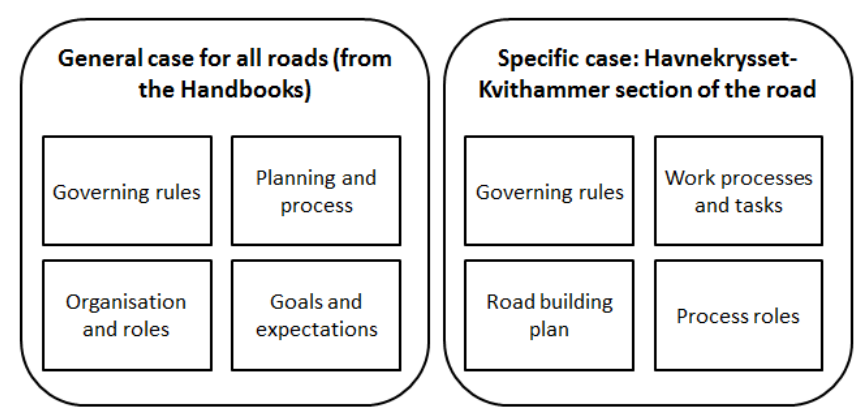

Fig. 2 - Overview of the model

${ }^{1}$ The METIS tool is now Troux Architect. For tool information see www.troux.com 
An overview of the actual model that was created is shown in Fig. 3. The lines between different objects indicate relationships among the objects and how they relate to or depend on each other. On the right hand side of the model which shows the specific model for the road section Havnekrysset - Kvithammer (the label translated as "Architecture for building plan Havnekrysset - Kvithammer"), there are numerous lines across the different contents in the model; e.g. the work processes and tasks are assigned to roles, the plan indicates which work processes are responsible for which parts and the plan is governed by rules and regulations. The viewing and filtering mechanisms of METIS make it possible to handle large models such as these with many relationships. The left hand part of the model (the label translated as "Architecture for planning and building roads") shows the generic information from several handbooks that are relevant for building the road section of interest which is modelled on the right hand side.

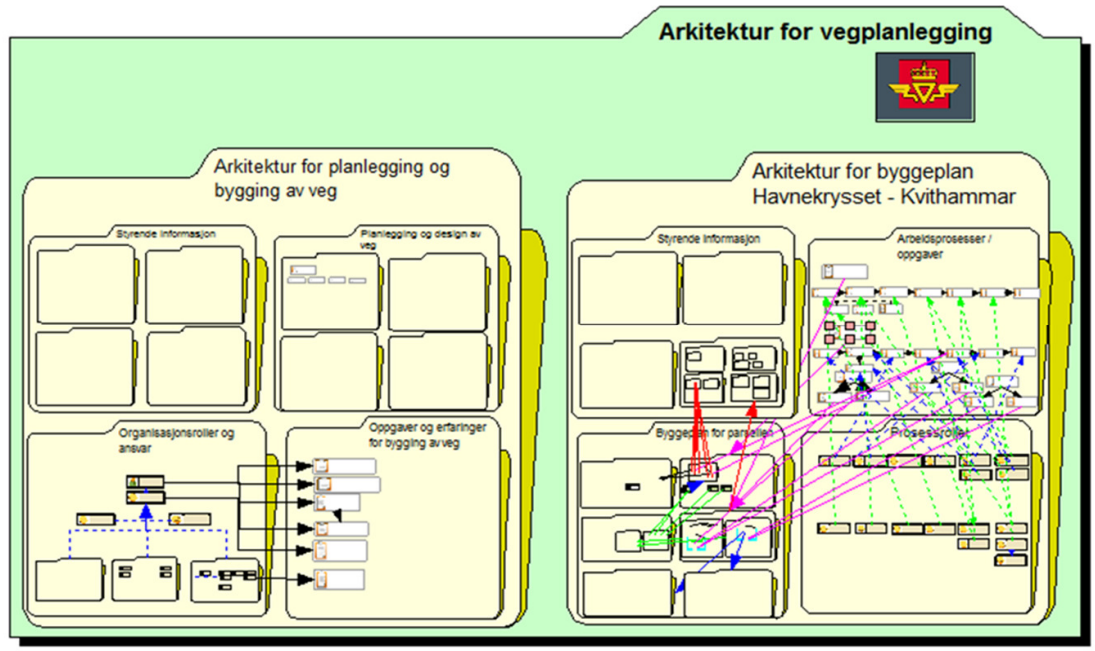

Fig. 3 - Generic and specific road planning and building architectures

\subsection{Modelling for Road Building: Architecture for Road Planning}

In this section, we will revisit some of the objectives of the modelling project from Section 3 to illustrate how the model achieves these:

- The contents in the Handbooks could become valuable knowledge models and reusable knowledge architectures.

- Active Knowledge Architectures could contribute to improved planning and building of roads through enhancing the visualization and sharing of knowledge among the people.

The governing information that is required for most roads and transport related projects are documented as Handbooks, which are currently available and textual 
documents, in paper and online. Accessing the right information from these Handbooks requires experience and knowledge about the domain and can take time. As mentioned earlier, the left hand side of the model shown in Fig. 3 contains generic information about road building. Parts of this model are shown in Fig. 4 and Fig. 5 where the left part of the both figures show governing information from these Handbooks. These specific parts refer to the relevant documents (live links are available from the model). How this governing information is used in the planning and designing of roads is shown in Fig. 4 while Fig. 5 how the project owner's tasks are governed to ensure that the project's goals and expectations are met.

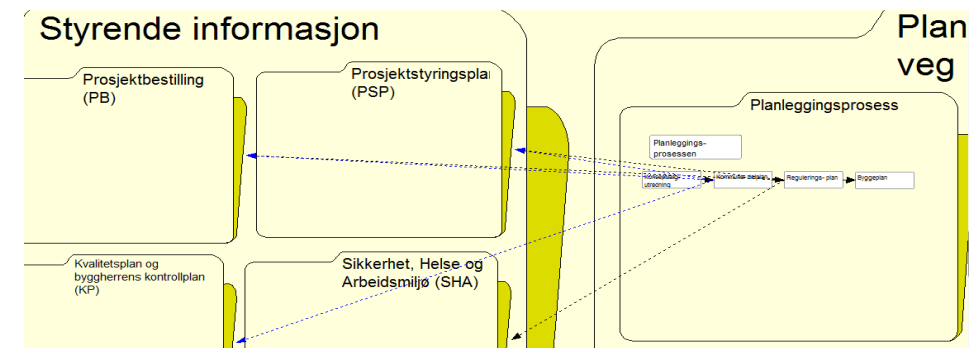

Fig. 4 - Contents of Handbooks used in planning

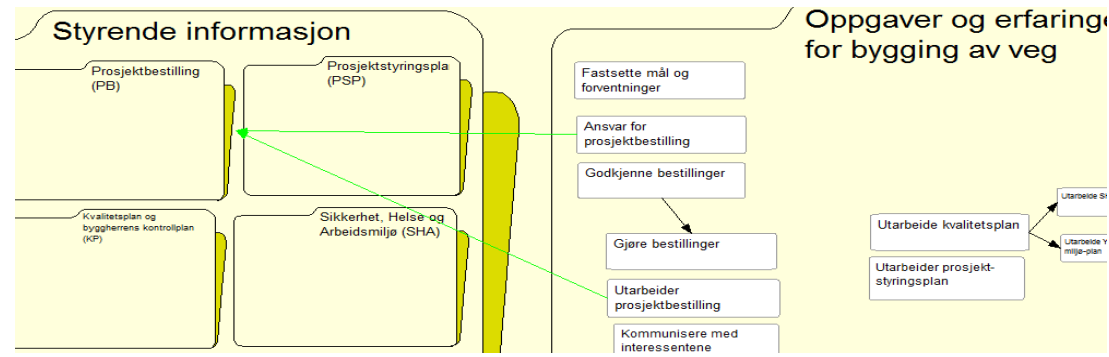

Fig. 5 - Contents of Handbooks used in meeting the goals of the project

During the discussions with the team from SVV, they highlighted the various public and private institutions that may be involved with project, which ranged from the police to private entrepreneurs. Similarly, the competence and expertise varied from technical to legal and design experiences. And most importantly, since these are often fairly large projects that span a long time period, (for example, there are cases that have spanned in the range of 30 years from the concept to the actual road in operation), the original planners, contractors of technical experts may not be around for the complete lifetime of the project. Thus, the need for making the knowledge visible and accessible to all became more and more evident throughout the project.

The information that is required to plan, design and build the specific road section is modelled in the right hand side of Fig. 3. As can be seen from the model, there are several relationships across the model which relate the different concepts. A simple 
example of such relationships is shown in Fig. 6. For example, the specific road section include a bridge and the process project description (the task "prosjektering") involves the roles of bridge building manager, the bridge expert and SVV's bridge planner. Similarly, externalisation of the knowledge from documents, handbooks or contracts, adapted and shared among several institutions and roles, enhances the existing knowledge among the people responsible. This facilitates the increase of competences among the individuals and teams, and sharing of knowledge. This in turn enhances the planning and execution of the project.

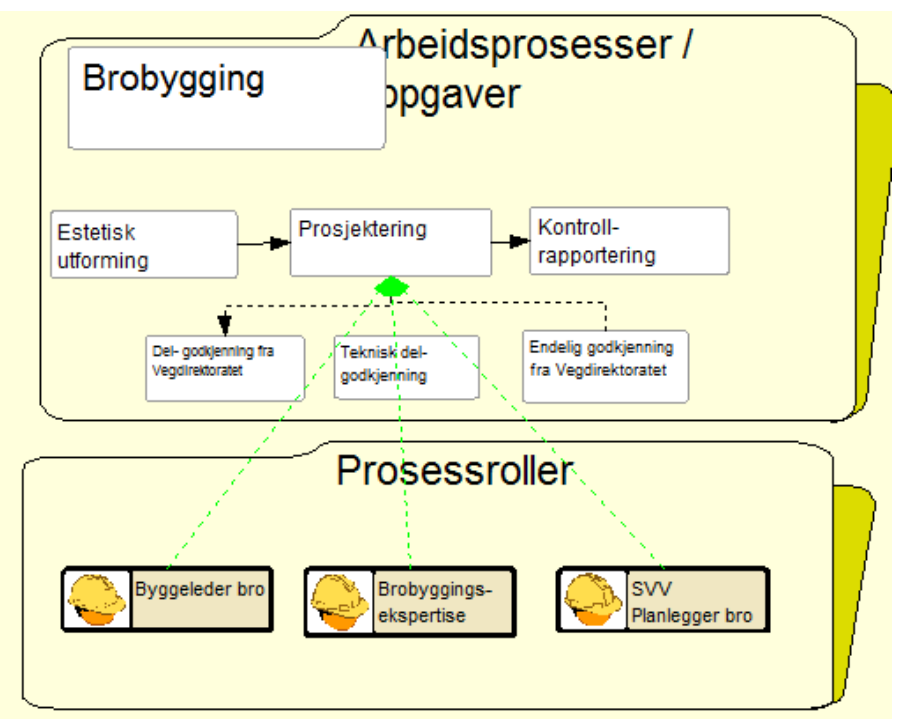

Fig. 6 - Relating work processes and roles

\subsection{Collaborative Networks}

The example process shown in Fig. 7, that for "skilting" or road signs, shows that the process involve actors from different organisations. The automatically generated relationship matrix shows how two sets of concepts relate to each other; e.g. the relationships between the different processes and roles, where the arrows in the cells show a relationship between two objects. The vertical axis shows the activities for creating a road sign such as the approval of the sign by SVV and the police and the announcement from the Municipality. The horizontal axis shows the actors that are involved, such as the Police, the Municipality and the producers of the road sign itself.

Almost all the processes in road planning, designing and building involves several actors from different organisations and this can be considered as a set of Virtual Enterprises [8] or Collaborative Networks [9]. Some of the most important features of Virtual Enterprises and Collaborative Networks include the communication and 
sharing of information among the collaborating partners. The characteristics of such organisations become relevant for road building also. Moreover, due to the long time span, the chances that the individual actors may change. Also, since different actors are involved in the different phases, there is a need to support the active participation of new actors and ensuring the transfer of the relevant knowledge across the actors. The AKM approach, through visualisation of knowledge, could provide the necessary knowledge base for the actors that are involved by providing them an overview of the project activities, their task descriptions and other relevant information for their work. This should contribute to a more effective working practice and better collaboration among the actors.

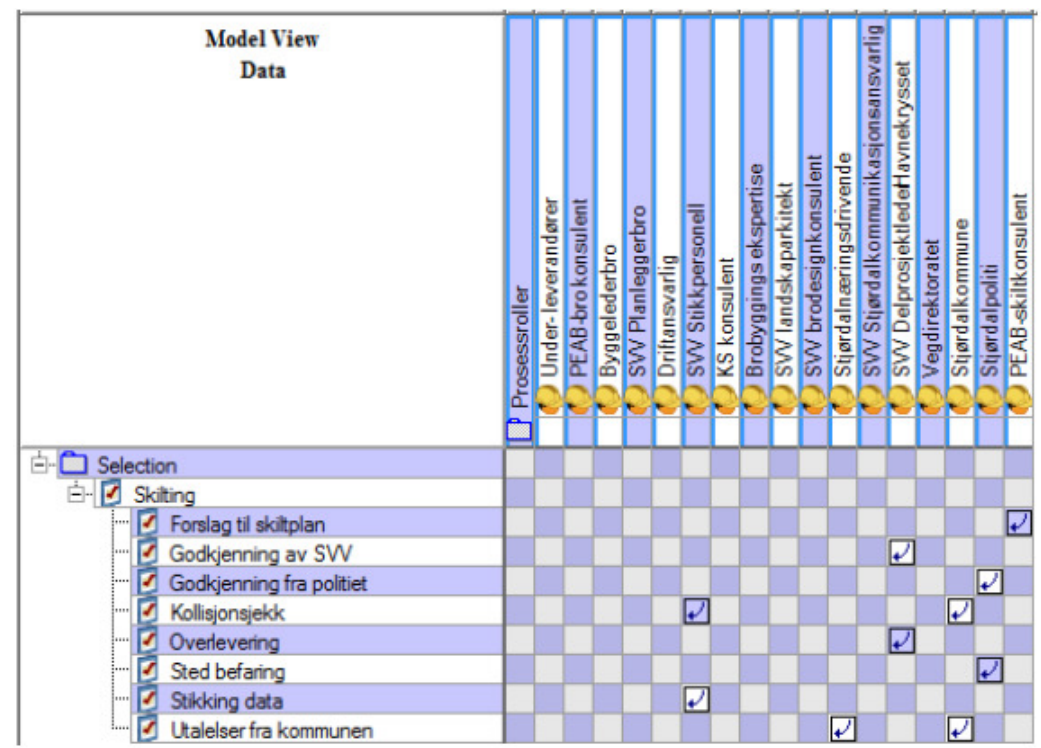

Fig. 7 - Relationship matrix of processes and roles from the model

Matrices such as these can be used to make various stakeholders aware of their roles and responsibilities and possibly to provide notifications as necessary. As can be seen from the figure, each activity involves several institutions and roles and the challenges in ensuring that all actors are aware of their roles in a timely manner can be challenging.

Whereas the initial model presented is not used in work execution, it has earlier been reported e.g. in [3] how models can be provided for users in model-driven work environments to be directly accessible and further evolved capturing new knowledge from the different stakeholders of the project. 


\subsection{Feedback on the Initial Model from SVV}

The validation of the model was done through regular meetings and getting feedback from the domain experts. Due to the lack of time and modelling experience of the expert from SVV, there was no opportunity for them to use the model. In total, six people from SVV participated in three meetings during the project period and the model was presented to them every time. During the final meeting, they were asked to respond to a questionnaire, which contained questions related to collaboration, increased understanding and faster work processes. Three people from SVV responded; their responses were based on the perceived benefits and the potential of the approaches. The scale used on the questionnaire is top, high, medium, low and minimal. The average responses to the questionnaire are presented in Table 1 .

Table 1 Summary of the questionnaire responses

\begin{tabular}{lll}
\hline & Questions & Score \\
\hline 1 & Enhanced collaboration and holistic thinking among roles and & High \\
& people & \\
2 & Collaboration with external parties, entrepreneurs and partners & High \\
3 & Reduced planning time & Medium \\
4 & Improved decision-support & Medium \\
5 & Improved quality control and follow up of plans and resources & Medium \\
6 & Traceability & Top \\
7 & Predictability & High \\
8 & Better understanding of approaches, methods and alternatives & Medium \\
9 & Competence transfer & High \\
10 & Support for training of new employees and partners & High \\
11 & Improved data, knowledge management and viewing & Top \\
12 & Reuse of architectures, models and knowledge assets & High \\
\hline
\end{tabular}

The responses to questions 1 and 2 indicate that modelling is a means to support collaboration across stakeholders and collaborative networks such as those that would exist between SVV and the entrepreneur that is contracted. Questions 3-7 relate to reducing the time taken for the project and if improved decision support and quality control. The responses to these questions were Medium while they all agreed (responded Top) that the model helped to improve traceability. They also gave a high score to support for competence transfer and support for training new employees. Similarly, improved data and knowledge management received a top score. Given that we have only feedback from very few people that has seen the initial model, and not been yet able to work within a model-generated workspace, this is only tentative input of course. However, it would be beneficial to have the model and the approach evaluated by a larger and more varied group of people.

Considering the fact that the validation was performed based on a 3 month modelling effort by a student, we regard these validations as good indications that model-based, architecture driven approaches and solutions have the potential to answer the questions they had asked. 


\section{Experiences and Lessons Learned}

Many experiences and practices learned are already included in section 3. For the SVV people participating in modelling the planning and building architectures, developing and using enterprise knowledge models was a new experience.

AKAs must be modelled from different perspectives: an agile approach capturing the workspaces, actions and decisions, of the roles designing the solution architecture and developing and adapting the methods to be applied. Emergent solutions and open extendable modeling and execution platforms are the other two fundamental knowledge dimensions, but there are more dimensions that will determine the design and construction rules of roads, other products and services.

Connecting the people that possesses the leading knowledge and experience from practical project work is always a major challenge as these people are always busy with ongoing projects. Organizational structures should include role-oriented structures, complementing the hierarchies and networks. Roles should be designed in order to create the best workspace tasks, views and data [10] and [11].

The four dimensions described in Fig. 8 are composed of reflective views and repeatable task-patterns [12]. Views from each of the above dimensions are mutually meta- and operational views for each other. The work plan is the meta-view for the work performer, and the performance is the meta-view for the planner.

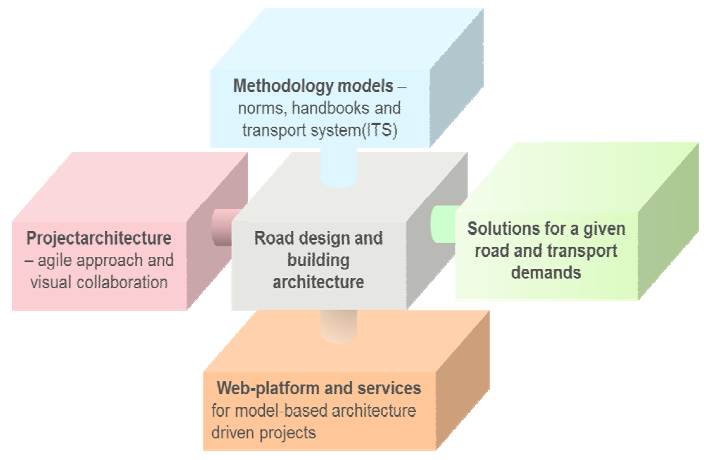

Fig. 8 - Future road building reference architectures

The project architecture, the road design and building architecture are independent architectures, but share many common knowledge models, like the overarching community transport strategy, design methods and role-oriented workspaces. Road planning, design and construction should be further researched to test out new collaborative design methods, applying holistic design principles and methods. 


\section{Summary}

Knowledge models were created by a modelling team for the Norwegian Road Authorities, with focus on a specific road section. The responses to a questionnaire indicate that the customer saw the potential benefits of this approach, which could be summarised as enhanced support for collaboration, support for reducing the time taken by SVV to do the work, improve quality and decision making and support for competence transfer and knowledge management. The responses from SVV indicate that AKAs and AKM could provide a number benefits in road the planning and designing processes. We plan to enhance this model and work towards establishing and evaluating role-based workspaces supported by AKAs. We also plan to show the enhanced model to more potential users and obtain a more detailed evaluation of the approach and the model. With access to more open platforms we hope to show the way towards novel and agile ways of designing collaborative road planning, design and building solutions.

\section{References}

1. Camarinha-Matos, L. and H. Afsarmanesh, Classes of Collaborative Networks, in Encyclopedia of Networked and Virtual Organizations, G.D. Putnik and M.M. Cunha, Editors. 2008, IGI Global. p. 193-198.

2. Vernadat, F.B., Enterprise Modelling and Integration Principles and Applications. 1996: Chapman and Hall.

3. Lillehagen, F. and J. Krogstie, Active Knowledge Modelling of Enterprises. 2008: Springer.

4. ATHENA. Advanced Technologies for Interoperability of Heterogeneous Enterprise Networks and their Applications. [cited 201514 June]; Available from: ftp://ftp.cordis.europa.eu/pub/ist/docs/directorate_d/ebusiness/athena.pdf.

5. Bui, V.M., Aktive kunnskapsmodellering for planlegging og bygging av veg, in Dept. of Computer and Information Science. 2013, Norwegian University of Science and Technology: Trondheim.

6. Lillehagen, F., The Foundations of AKM Technology in 10th International Conference on Concurrent Engineering (CE). 2003: Madeira, Portugal.

7. Persson, A. and J. Stirna, Towards Defining a Competence Profile for the Enterprise Modelling Practitioner, in PoEM 2010, P. van Bommel, Ed.. 2010, Springer. p. 232-245.

8. Petersen, S.A., Virtual Enterprise Formation and Partner Selection: An Analysis Using Case Studies. International Journal of Networking and Virtual Organisations 2007. 4(2): p. 201-215.

9. Camarinha-Matos, L. and H. Afsarmanesh, Collaborative networks: a new scientific discipline. Journal of Intelligent Manufacturing, 2005. 16: p. 439-452.

10. Jørgensen, H.D. and J. Krogstie, Active Models for Dynamic Networked Organisations, in CAiSE 2001. 2001, Springer.

11. Krogstie, J. and H.D. Jørgensen, Interactive Models for Supporting Networked Organization, in CAiSE'2004. 2004, Springer.

12. Sandkuhl, K. and J. Stirna, Evaluation of task pattern use in web-based collaborative engineering, IEEE, in Proceedings of the 34th EUROMICRO 2008, IEEE. 